\title{
MULTIPLICITY OF 2-NODAL SOLUTIONS FOR A SEMILINEAR ELLIPTIC EQUATION
}

\author{
TSUNG-FANG WU
}

Abstract. In this paper, we consider the multiplicity of 2-nodal solutions of semilinear elliptic equations. Using the generalized barycenter map, we prove that existence of multiple 2-nodal solutions for semilinear elliptic equations in some domains with hole.

Mathematics subject classification (2000): 35J60, 35J20, 35J25.

Keywords and phrases: semilinear elliptic equations, multiple nodal solutions, Palais-Smale.

\section{REFERENCES}

[1] A. Ambrosetti And P. H. Rabinowitz, Dual variational methods in critical point theory and applications, J. Funct. Anal., 14 (1973), 349-381.

[2] A. BAHRI AND P. L. LIONS, On the existence of positive solutions of semilinear elliptic equations in unbounded domains, Ann. Inst. H. Poincaré Anal. Non Lineairé, 14, 3 (1997), 365-413.

[3] T. BARTSCH, Critical point theory in partially ordered Hilbert spaces, J. Funct. Anal., 186 (2001), $117-152$.

[4] T. BARTSCH AND T. WETH, Three nodal solutions of singularly perturbed elliptic equations on domains without topology, Ann. Inst. H. Poincaré Anal. Non Linéaire, 22 (2005), 259-281.

[5] V. Benci AND G. CERAmi, Positive solutions of some nonlinear elliptic equations in exterior domain, Arch. Ration. Mech. Anal., 99 (1987), 283-300.

[6] H. Berestycki AND P. L. Lions, Nonlinear scalar field equations. I. Existence of ground state, Arch. Ration. Mech. Anal., 82 (1983), 313-345.

[7] H. BRÉZIS AND E. H. LIEB, A relation between pointwise convergence of functions and convergence of functionals, Proc. Amer Math. Soc., 88 (1983), 486-490.

[8] A. Castro AND M. Clapp, The effect of the domain topology on the number of minimal nodal solutions of an elliptic equation at critical growth in a symmetric domain, Nonlinearity, 16 (2003), 579-590.

[9] K. C. Chen, K. J. Chen ANd H. C. WANG, Symmetry of positive solutions of semilinear elliptic equations on infinite strip domains, J. Differential Equations, 148 (1998), 1-8.

[10] G. CERAMI AND D. PASSASEO, The effect of concentrating potentials in some singularly perturbed problems, Calc. Var., 17 (2003), 257-281.

[11] M. ClapP AND T. WeTh, Minimal nodal solutions of the pure critical exponent problem on a symmetric doamin, Calc. Var. Partial Differential Equations, 21 (2004), 1-14.

[12] M. Del Pino AND P. L. Felmer, Local mountain passes for semilinear elliptic problems in unbounded domains, Calc. Var. Partial Differential Equations, 4 (1996), 121-137.

[13] M. Del Pino And P. L. Felmer, Least energy solutions for elliptic equations in unbounded domains, Proc. Roy. Soc. Edinburgh Sect. A, 126 (1996), 195-208.

[14] M. J. ESTEBAN AND P. L. LiONS, Existence and non-existence results for semilinear elliptic problems in unbounded domains, Proc. Roy. Soc. Edinburgh Sect. A, 93 (1982), 1-12.

[15] M. F. FURTADO, A relation between the domain topology and the number of minimal nodal solutions for a quasilinear elliptic problem, Nonlinear Analysis, 62 (2005), 615-628.

[16] M. F. FURTADO, A note on the number of nodal solutions of an elliptic equation with symmetry, Applied Mathematics Letters, 19 (2006), 326-331. 
[17] H. C. HUANG AND T. F. WU, Four 2-nodal solutions for a semilinear elliptic equation in a finite strip with a hole, J. Math. Anal. Appl., 328 (2007), 567-576.

[18] M. K. Kwong, Uniqueness of positive solution of $\Delta u-u+u^{p}=0$ in $\mathbb{R}^{N}$, Arch. Rat. Math. Anal., 105 (1989), 243-266.

[19] W. C. LIEN, S. Y. TZENG AND H. C. WANG, Existence of solutions of semilinear elliptic problems in unbounded domains, Differential Integral Equations, 6 (1993), 1281-1298.

[20] P. L. Lions, The concentration-compactness principle in the calculus of variations. The local compact case, Ann. Inst. H. Poincaré Anal. Non Lineairé, 1 (1984), 102-145 and 223-283.

[21] Z. Q. WANG, On a superlinear elliptic equation, Ann. Inst. H. Poincaré Anal. Non Linéaire, 8 (1991), $43-57$.

[22] H. C. WANG AND T. F. WU, Symmetry breaking in a bounded symmetry domain, NoDEA-Nonlinear Differential Equations Appl., 11 (2004), 361-377.

[23] M. WiLlem, Minimax Theorems, Birkhäuser, Boston, 1996.

[24] T. F. Wu, Multiple positive solutions for semilinear elliptic equations in Esteban-Lions domains with holes, Taiwanese Journal of Math., 9, 2 (2005), 245-260.

[25] T. F. WU, The effect of domain shape on the number of positive and nodal solutions for semilinear elliptic equations, Nonlinear Analysis T.M.A., 67 (2007), 2609-2622.

[26] T. F. WU, Existence and multiplicity of nodal solutions for Dirichlet problems in upper half strip with holes, Nonlinear Analysis T.M.A., 69 (2008), 2167-2178.

[27] E. ZEIDLER, Nonlinear functional analysis and it Applications I, Fixed-point theorems, Springer, New Yourk, 1986. 